Grande: None. R. Crosa: None. S. Webb: None. M. Psychogios: None. E. Peterson: None. D. Yavagal: None. A. Spiotta: 1; C; Penumbra, Medtronic, Stryker. 2; C; Cerenovus, Terumo, Siemens, Penumbra, Stryker. R. Starke: 1; C; NREF, Joe Niekro Foundation, Brain Aneurysm Foundation, Bee Foundation, NIH, Miami Clinical and Translational Science Institute, National Center for Advancing Translational Sciences, National Institute on Minority Health and Health Disparities. 2; C; Penumbra, Abbott, Medtronic, InNeuroCo, Cerenovus.

\section{P-009 AN ANGLED TIP IS ASSOCIATED WITH IMPROVED TECHNICAL OUTCOMES WHEN USING 0.064-0.074 ASPIRATION CATHETERS: ANALYSIS FROM A MULTICENTER RETROSPECTIVE COHORT}

${ }^{1} \mathrm{~J}$ Vargas*, ${ }^{2} \mathrm{~S}$ Majidi, ${ }^{3} \mathrm{H}$ Hawk, ${ }^{4} \mathrm{~S}$ Nimjee, ${ }^{4} \mathrm{~A}$ Zakeri, ${ }^{5} \mathrm{M}$ Mokin, ${ }^{6} \mathrm{R}$ Kellogg, ${ }^{7} \mathrm{G}$ Cortez, ${ }^{7} \mathrm{~A}$ Aghaebrahim, ${ }^{7} \mathrm{E}$ Sauvageau, ${ }^{8} \mathrm{R}$ Hanel, ${ }^{9} \mathrm{R}$ De Leacy, ${ }^{10} \mathrm{~A}$ Siddiqui, ${ }^{11} \mathrm{~A}$ Turk, ${ }^{12} \mathrm{M}$ Oselkin, ${ }^{13} \mathrm{E}$ Marlin, ${ }^{14} \mathrm{R}$ Turner, ${ }^{14} \mathrm{I}$ Chaudry, ${ }^{15} \mathrm{~J}$ Milburn. ${ }^{1}$ Neurosurgery, Southeastern Neurosurgery and Spine, Greenville, SC; ${ }^{2}$ Neurosurgery, Mount Sinai Hospital, New York, NY; ${ }^{3}$ Radiology, Erlanger Health System, Chattanooga, TN; ${ }^{4}$ Neurosurgery, The Ohio State University Medical Center, Columbus, OH; ${ }^{5}$ Neurosurgery, Tampa General Hospital, Tampa, FL; ${ }^{6}$ Neurosurgery, University of Virginia, Charlottesville, VA; ${ }^{7}$ Neurosurgery, Baptist MC, Jacksonville, FL; ${ }^{8}$ Neurosurgery, Baptist Health, Jacksonville, FL; ${ }^{9}$ Neurosurgery, Mount Sinai, New York, NY; ${ }^{10}$ Neurosurgery, University of Buffalo, Buffalo, NY; ${ }^{11}$ Neurosurgery, MUSC, Greenville, SC; ${ }^{12}$ Radiology, St Luke's University, Bethlehem, PA; ${ }^{13}$ Neurosurgery, St Luke's University, Bethlehem, PA; ${ }^{14}$ Neurosurgery, Prisma Health, Greenville, SC; ${ }^{15}$ Radiology, Ochsner Health, New Orleans, LA

\subsection{6/neurintsurg-2021-SNIS.45}

Background Recent introduction of large bore aspiration catheters have contributed to high reperfusion rates. The alteration of these catheters to have angled tips, which increase clot engagement area by approximately $15 \%$, has been suggested to improve rates of complete clot ingestion, resulting in higher quality thrombectomies. We aimed to evaluate the recanalization efficacy of new generation angled tip aspiration catheters in comparison to commonly used straight tip aspiration catheters in real world data set.

Methods We performed a multicenter retrospective analysis of consecutive acute ischemic stroke patients with M1 occlusion treated within 24 hours from the time of last known well. Patients were divided into two cohorts: those in whom a 0.071 angled tip catheter was the initial device used to attempt reperfusion and those in whom a 0.064-0.074 inch flat tip (non-angled) catheter was the initial device used to attempt reperfusion. The primary outcome was the rate of excellent reperfusion (TICI 2C). Secondary outcomes included the rate of successful reperfusion (TICI2B), use of stent retrievers, and access to successful reperfusion time. All data was self-adjudicated. No outside funding was provided for this analysis.

Results Total of 650 patients with acute M1 occlusion who underwent thrombectomy were identified. Angled tip Zoom 71 catheter was used in 162 patients, while 488 patients were treated with flat tip aspiration catheters (ranging 0.064 to 0.074 inch in inner diameter). The baseline mRS score, admission NIHSS score, the rate of intravenous thrombolytic therapy, symptom onset to hospital arrival, and use of anesthesia were not different between the cohorts. The primary outcome was significantly higher in the angled tip cohort $(67 \%$ vs $59 \%, \mathrm{p}=0.03)$. There was no difference in the rate of TICI2B reperfusion $(96 \%$ vs $94 \%, p=0.71)$. There was a lower rate of stent retriever use $(25 \%$ vs $44 \%, \mathrm{p}<.0001)$ in the angled tip cohort. Access time to successful reperfusion was significantly faster with angled tip catheters (21 vs 29 minutes, $\mathrm{p}<.0001)$. Access time to TICI $2 \mathrm{~B}(25$ vs 31 minutes, $\mathrm{p}=0.03$ ) and final recanalization ( 29 vs 35 minutes, $\mathrm{p}=0.03$ ) remained significantly shorter in the angled tip cohort, after adjusting for age, thrombectomy technique, use of secondary aspiration catheter.

Conclusion This multicenter, consecutive real-world experience demonstrates that M1 thrombectomy with an angled tip aspiration catheter is associated with higher rates of TICI $2 \mathrm{C}$ or better reperfusion, equal rates of TICI $2 \mathrm{~B}$ or better reperfusion, and faster time to successful reperfusion.

Disclosures J. Vargas: None. S. Majidi: None. H. Hawk: None. S. Nimjee: None. A. Zakeri: None. M. Mokin: None. R. Kellogg: None. G. Cortez: None. A. Aghaebrahim: None. E. Sauvageau: None. R. Hanel: None. R. De Leacy: None. A. Siddiqui: None. A. Turk: None. M. Oselkin: None. E. Marlin: None. R. Turner: None. I. Chaudry: None. J. Milburn: None.

\section{P-010 FIRST LINE DIRECT CONTACT ASPIRATION VERSUS STENT-RETRIEVER BASED TECHNIQUES: REAL-WORLD COMPARATIVE THROMBECTOMY OUTCOMES FROM THE NVQI-QOD ACUTE ISCHEMIC STROKE REGISTRY}

${ }^{1} \mathrm{~A}$ Mahapatra*, ${ }^{2} \mathrm{Y}$ Moazeni, ${ }^{1} \mathrm{~T}$ Patterson, ${ }^{2} \mathrm{R}$ Abdalla, ${ }^{3} \mathrm{~J}$ Tsai, ${ }^{1} \mathrm{~N}$ Moore, ${ }^{1} \mathrm{M}$ Bain, ${ }^{1} \mathrm{G}$ Toth, ${ }^{2} \mathrm{~S}$ Ansari, ${ }^{1} \mathrm{M}$ Hussain. ${ }^{1}$ Cerebrovascular Center, Cleveland Clinic Foundation, Cleveland, OH; ${ }^{2}$ Radiology, Northwestern University, Chicago, IL; ${ }^{3}$ Neurology, Spectrum Health, Grand Rapids, MI

\subsection{6/neurintsurg-2021-SNIS.46}

Introduction Mechanical thrombectomy is the standard of care treatment for large-vessel acute ischemic stroke and associated with significant improvement in long-term functional outcomes. Early and complete recanalization are paramount in achieving optimal patient outcomes. Though several revascularization techniques have been described, direct contact aspiration and clot removal via stent-retriever remain the foundation of endovascular stroke thrombectomy. Utilizing the NeuroVascular Quality Initiative - Quality Outcomes Database (NVQI-QOD) Acute Ischemic Stroke Registry, we present realworld data on first-line practice for treatment of emergent large vessel occlusions (ELVOs), comparing angiographic and clinical outcomes between direct contact aspiration and stentretriever mechanical thrombectomy techniques.

Methods Retrospective analysis of the NVQI-QOD registry data was performed. We included patients with ELVOs that underwent mechanical thrombectomy with age $>18$ years and presenting NIHSS $\geq 6$. We compared procedural times, recanalization efficacy, and clinical outcomes, including in-hospital mortality and discharge NIHSS.

Results We identified a total of 2381 patients that met inclusion criteria. 998 (41.9\%) underwent treatment with direct contact aspiration alone and 1383 (58.1\%) underwent treatment utilizing a stent-retriever (with or without local aspiration). There were no significant differences in baseline median NIHSS scores (16 vs. $17, \mathrm{p}=0.25)$ or median ASPECTS scores ( 9 vs. $9, p=0.7)$. No significant differences were seen in time last known well to puncture times (282 $\mathrm{min}$ vs. 280 $\min , \mathrm{p}=0.22)$ or recanalization time $(323 \mathrm{~min}$ vs. $322 \mathrm{~min}$, $\mathrm{p}=0.39)$, ED to puncture time $(75 \mathrm{~min}$ vs. $71 \mathrm{~min}, \mathrm{p}=$ $0.25)$ or recanalization time $(158 \mathrm{~min}$ vs. $160 \mathrm{~min}, \mathrm{p}=$ $0.55)$, or median procedure times between the two groups (23 